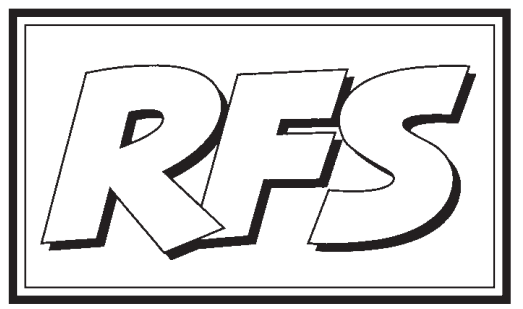

Revista de Fomento Social, 57 (2002), 435-471

\title{
Vietnam: en busca de una tercera vía
}

Gaspar RUL-LÁN BUADES ${ }^{1}$

\section{Una historia turbulenta}

\subsection{Mil años de dominación china}

Hubo que esperar hasta la proclamación, el 2 de julio de 1976, de la actual República Socialista de Vietnam, esta estrecha franja de 1.700 kms del oeste de la antigua Indochina, y que en sus $332.000 \mathrm{Km}$ cuadrados de superficie, comprende las tres regiones denominadas por los franceses Tonkin, en el norte, Annam en el centro y Conchinchina en el sur, para que este país pudiera disfrutar de una plena unificación e independencia. Casi mil años de lucha por construir el actual Vietnam han forjado un pueblo de 78 millones de gentes disciplinadas, responsables y trabajadoras.

1 El autor lleva tres años colaborando, junto con otros profesores de ETEA, con las Universidades de Hanoi y Thai Nguyen, en un proyecto de desarrollo rural. 
El valle del río Rojo en el norte estuvo habitado desde tiempo inmemorial, y algunas localidades vietnamitas han dado nombre a las culturas prehistóricas y protohistóricas que florecieron en Indochina a partir del V milenio a.C. A finales del siglo III a.C. se inició en la región de Tonkin la dominación china, que duró más de mil años, hasta el año 939 d.C. Este largo período de ocupación no pudo menos que dejar una profunda huella en la cultura del país: las estructuras sociales chinas, el Confucionismo como ideología del Estado, la difusión del budismo, la adopción de la lengua y la escritura china y la introducción de las técnicas agrarias y metalúrgicas. Mientras tanto, en el delta del Mekong, en el sur, a finales del siglo Il d.C secreó el reino de Funan, bajo la influencia de ideas Ilegadas de la India, como lo demuestran sus restos arqueológicos: estatuas de Buda de influencia gupta y símbolos de los dioses hindúes Shiva y Vishnu. En medio de estas dos culturas, en el centro del moderno Vietnam se desarrollaba el reino de Champa, con una cultura mezcla de caracteres autóctonos, chinos e indios, que mantuvo buenas relaciones con China pero que, constantemente amenazado por sus vecinos del norte, se vio forzado a extenderse hacia el sur.

La crisis de la dinastía china de los T'ang señaló el fin de su do minio sobre Dai Viet, nombre con que se conoció Vietnam hasta el siglo XIX. El largo dominio chino fue seguido de una serie de dinastías feudales, como la de los Ly y las de los Tran, inmersas en continuas luchas internas, hasta que en 1428 se estableció la dinastía de los Le. El reinado de uno de sus reyes, Le Thanh Ton (1460-1497) fue un período de gran apogeo militar y cultural. Este rey, siendo un gran amante de las letras apoyó distintos movimientos literarios tanto en chino, que era la lengua de la corte, como el desarrollo de una literatura en lengua vietnamita aunque transcrita todavía en caracteres chinos (el nom). También en su tiempo el Confucionismo se adoptó como doctrina oficial del Estado. La gran figura de la época fue Nguyen Trai quien, al presentarse por primera vez ante el monarca para ofrecer sus servicios, le dedicó una serie de dichos de profunda sabiduria oriental: "vale más conquistar los corazones que las ciudades"; "asegurar la paz al pueblo, tales son los fundamentos de las virtudes de humanidad y justicia"; " cuando se disfruta de grandes prebendas, hace falta pensar en los que trabajan"; "quien porta el trono, como el océano sostiene el barco, pero también pude hundirlo".2

En el siglo XVI dos grandes familias nobles, los Trinh en el norte, y los

2 Naguyen Kac Vien (1997) p. 91. Esta es una historia de Vietnam quasi oficial que puede encontrarse en todas las librerías de Hanoi traducida a la mayoría de los idiomas europeos. 
Nguyen en el sur, llegaron a dominar a los reyes de la dinastía Le, creando una situación de debilidad política en el país que propició la penetración de los europeos, pues mientras la familia del norte buscó el apoyo de los holandeses, la del sur se relacionó con los portugueses y franceses que empezaron a mandar misioneros. Fueron estos primeros misioneros los que idearon un sistema para transcribir la lengua vietnamita en caracteres latinos, el Ilamado "quoc-ngu", y que perfeccionó más tarde el misionero jesuita Alexandre de Rhodes preparando el primer diccionario annamita-castellano-latín.

En 1771 el descontento popular contra los Trihn del norte y los Nguyen del sur se materializó en la sublevación de los hermanos Tay Son (el nombre de su lugar de origen) quienes derrotando a las dos familias restablecieron la unidad del país y proclamaron emperador a su líder Nguyen Hue, quien tomó el nombre de Qung Trung (1778) e inició un período de gran prosperidad para el país. Pero pronto el país se vio de nuevo envuelto en otra guerra civil que terminó con el establecimiento de la última dinastía de reyes vietnamitas que reinó hasta 1945. Fue durante el reinado de alguno de estos reyes de la dinastía Nguyen, educados en un estricto confucionismo, que se desataron crueles persecuciones contra los católicos que llevaron en 1830 a la ejecución de varios misioneros extranjeros y numerosos católicos. Cuando, finalmente, en 1857 fue asesinado el obispo español J osé María Díaz Sanjurjo, la Francia de Napoleón III con la ayuda de la España de Isabel II decidió intervenir directamente en Vietnam.

\subsection{Período colonial}

En 1858, 59 barcos de la flota francesa y un barco de guerra español llegado de Filipinas con 1.200 soldados de esta nacionalidad, desembarcaron en la actual Danang a la que conquistaron en pocos días iniciándose así el siglo de colonialismo galo en Vietnam. En 1859, con la ayuda de las tropas españolas, Francia conquistó Saigón y las tierras circundantes, y en 1862, Francia obligó al emperador a firmar un acuerdo por el que cedía la desembocadura del Mekong y hacía importantes concesiones comerciales, mientras se le obligaba también a pagar una elevada indemnización. En los cinco años siguientes, el gobernador de Saigón ocupó todo el sur del país (la Conchinchina) más tarde convertida en colonia de Francia. En 1872, el aventurero francés Dupuis, sin pedir permiso a las autoridades vietnamitas, se atrevió a remontar el río Rojo con un cargamento de armas para un general chino y, cuando las autoridades del país intentaron impedírselo, el gobierno francés envió un 
ejército a Hanoi y declaró, contra la voluntad del gobierno y el pueblo vietnamita, la libre navegación por el río Rojo. A estos hechos siguió la conquista por Francia, ayudada por grupos vietnamitas católicos, de la región norteña conocida como Tonkin, consiguiendo en 1883 imponer a la corte vietnamita un tratado que convertía el norte, Tonkin, y el centro del país, Annam, en protectorados franceses. Finalmente, en 1887 Vietnam fue incluido en una Unión Indochina junto con Camboya y Laos.

Pero desde el primer día de la conquista francesa se originó una enconada lucha contra este poder colonial. En 1927 surgió el primer partido nacionalista del país, el Viet-Nam Quoc Dan Dang (VNQDD) de ideas tanto anticolonialistas como antico munistas, y en 1930 secreó el Partido Comunista Indochino bajo la dirección de Nguyen Ai Quoc, más conocido como Ho Chi Minh. Al inicio de la segunda guerra mundial, después de la invasión de Francia por el ejército alemán, el gobierno pronazi de Vichy firmó una serie de convenios de colaboración con el gobierno japonés, dando a éste ciertos derechos sobre Vietnam. Terminada la segunda guerra mundial, al rendirse las últimas tropas japonesas, el ejército chino de Tchang Kai Chek entró en Vietnam por el norte hasta el paralelo 16, mientras que el sur quedaba bajo el control británico. Aprovechando el descontento de la población por esta nueva división del país, Ho Chi Minh creó la Liga Patriótica para la Independencia de Vietnam, más conocida como "Vietminh" y que más tarde tendría que jugar un papel fundamental en el enfrentamiento con Estados Unidos. Desde su fundación el Vietminh concentró todos sus esfuerzos en el norte del país, pudiendo, ya en 1943, crear una "zona libre" en las montañas de Tonkin en la que fue consolidand o y extendiendo su poder, de manera que cuando en 1945 el Japón fue derrotado y tuvo que retirarse de todas sus posiciones en Asia oriental, el Vietminh se había convertido ya en la única fuerza política bien organizada de Vietnam, que pudo el 2 de septiembre de 1945, después de la abdicación del emperador Bao Dao, declarar la independencia de la República Democrática de Vietnam. El nuevo gobierno convocó inmediatamente elecciones generales y el Vietminh obtuvo una mayoría en la nueva Asamblea Nacional. Francia reconoció, aunque de mala gana, la nueva República Democrática de Vietnam como Estado libre dentro de la Unión Francesa, aunque en el sur del país trabajaba para fomentar un movimiento secesionista de Conchinchina y para implantar un gobierno afín a los intereses de la metrópolis.

La restaurada Francia del general de Gaulle no estaba dispuesta a perder tan fácilmente su poder en Extremo Oriente. Sólo un año después de recono- 
cer a la nueva República Democrática de Vietnam, Francia inició una verdadera guerra de reconquista que le llevó de derrota en derrota a pesar de la ayuda norteamericana que empezaba a sentirse en aquel país. En octubre de 1946 se redactó la primera Constitución nacional de un Vietnam unificado de norte a sur. Los gobernantes franceses no la aceptaron y atacaron el puerto de Haiphong, siendo respondidos por un ataque vietnamita a la guarnición francesa de Hanoi, iniciándose así otra guerra del sufrido pueblo vietnamita por su independencia. En 1949 Francia restableció en el trono al emperador Bao Dai y proclamó un gobierno nacional independiente del gobierno del Vietminh. El triunfo de la revolución China y la creación de la República Popular China en 1949 supuso un gran apoyo para el gobierno de Ho Chi Minh que fue reconocido diplomáticamente por Rusia y los otros países del bloque comunista. La guerra de la independencia vietnamita fue una serie de conquistas de las fuerzas nacionalistas sobre el ejército francés que, finalmente, fue totalmente derrotado en el famoso puesto de Dien Bien Phu el 7 de mayo de 1954. Mientras tanto, la guerra fría se había iniciado y la suerte de Vietnam debía ser decidida según los intereses de las dos potencias enfrentadas. En la Conferencia de Ginebra de mayo de 1954 se acordó la retirada absoluta de las fuerzas francesas de Vietnam y se reconoció la independencia del país con un período transitorio de dos años en los cuales el paralelo 170N separaría el norte del país en manos de las fuerzas del Vietminh delas fuerzas coloniales del sur, hasta que se celebrasen elecciones generales que reunificasen el país y decidiesen el régimen de gobierno deseado.

\subsection{Guerra del Vietnam}

Pero esta solución no fue del agrado de Estados Unidos que deseaba mantener el sur de Vietnam libre del peligro comunista, y por ello se negó a firmar los acuerdos de Ginebra y empezó a apoyar al gobierno secesionista que se había formado en Saigón presidido por Ngo Dinh Diem, quien, con la ayuda militar y económica norteamericana, consiguió convocar un plebiscito cuyo resultado fue la deposición del legítimo emperador Bao Dai y la Proclamación de la República de Vietnam del Sur con él como Presidente.

La negativa de convocar las elecciones que había previsto la Conferencia de Ginebra junto con el nepotismo y corrupción del gobierno de Ngo Dinh Diem y la decisión del gobierno de concentrar a los campesinos en "aldeas estratégicas" que pudiesen ser mejor vigiladas por la policía y el ejército para 
evitar cualquier infiltración de ideas comunistas, tuvieron como resultado crear un profundo descontento en la población rural que buscó su apoyo en los guerrilleros del sur y en el gobierno del norte. En 1960 todas las fuerzas de resistencia del sur del país se juntaron para crear el Frente Nacional de Liberación o Vietcong. El Presidente Ngo Dinh Diem, fanático católico, se enfrentó con las organizaciones budistas lo que aumentó de tal manera el descontento popular que, finalmente, las autoridades estadounidenses de Saigón propiciaron un golpe de Estado que el 1 de noviembre de 1963 derrocó y dio muerte al Presidente Diem y a su hermano Nhu. Pero las divisiones en el seno delas fuerzas anticomunistas siguieron manifestánd ose con una serie de golpes de Estado que se sucedieron entre 1963 y 1965 que terminaron con el establecimiento de un gobierno militar con Nguyen Van Thieu como Presidente.

Viendo que el Vietcong del sur iba ganando terreno apoyado por el comunista Vietminh del norte, Estados Unidos de América decidió entrar en una peligrosa dinámica que le llevaría a una de las más largas y crueles guerras de los tiempos modernos y que terminó con la total derrota del gigante norteamericano. Deseando presionar al gobierno de Ho Chi Minh para que ejerciera su influencia sobre los guerrilleros del sur a fin de poder terminar su agresión, Estados Unidos inició una serie de bombardeos aéreos contra centros neurálgicos de Vietnam del Norte que, informó, sólo cesarían con la liquidación total de las fuerzas guerrilleras del Vietcong. Pero ni este sucio chantaje ni el ejército gubernamental de Saigón eran capaces de parar las fuerzas del Vietcong apoyadas por toda la población campesina del delta del Mekong. El fracaso de esta política forzó a Estados Unidos de América a implicarse directamente en el conflicto enviando cada vez mayores contingentes de soldados y armamento bélico. En el verano de 1965 entraron en el país las primeras tropas estadounidenses llegando en pocos meses a ser más de 75.000 y más de medio millón tres años más tarde. A principios de 1968 el Vietcong, bajo la dirección del famoso general conocido como Giap (coraza) lanzó la famosa "ofensiva del Tet" que supuso un verdadero descalabro de las fuerzas militares conjuntas del ejército gubernamental del sur y el poderío militar norteamericano. Ante tal fracaso militar, Estados Unidos propuso a Hanoi un inicio de conversaciones de paz que el gobierno de Ho Chi Minh inmediatamente aceptó, iniciándose éstas en París en mayo de 1968, consiguiendo que en noviembre el presidente Johnson ordenase el cese de los bombardeos sobre Vietnam del norte. Con la llegada de Nixon en 1969 a la presidencia y la muerte de Ho Chi Minh, comenzó una nueva fase en la guerra 
de Vietnam. Ante las crecientes bajas que sufría el ejército norteamericano en Vietnam y la presión antiguerra que se había generado en el propio país, Nixon decidió que era conveniente "vietnamizar" la guerra, es decir, dejar que fuesen los soldados survietnamitas los que luchasen con el apoyo sólo económico y técnico de Washington. Pero ante el miedo de que se repitiese otra traición como la que se dio después de la Conferencia de Ginebra, Hanoi siguió apoyando al movimiento guerrillero de liberación del sur, el Vietcong, y Estados Unidos siguió bombardeando el Vietnam del norte con la idea de cortar definitivamente la famosa "ruta Ho Chi Minh" que abastecía al Vietcong a través de Laos. Finalmente el 27 de enero de 1973 se firmó en París el acuerdo por el que las fuerzas norteamericanas abandonaban Vietnam y se dejaba a los gobiernos de Hanoi y Saigón decidir el futuro del país una vez terminadas las hostilidades, pero éstas continuaron todavía dos años más hasta que el 30 de abril de 1975 las fuerzas del Frente Nacional de Liberación entraron en Saigón poniendo fin a la guerra, lo que supuso para Vietnam el inicio, después de siglos de guerra y dominación extranjera, de un nuevo perío do de su historia caracterizado por la unión de to da Vietnam en un solo Estado bajo un gobierno socialista. Esta fue, sin duda, una de las guerras más absurdas y sangrientas del siglo XX, que supuso el desplazamiento a Vietnam de más de tres millones de soldados desde 1965, de los que unos 60.000 murieron o desaparecieron; casi medio millón de nortvietnamitas y 200.000 survietnamitas perdieron la vida y más de tres millones de civiles vietnamitas murieron o fueron heridos.

\section{Un sistema político en transición}

\subsection{La República Socialista de Vietnam}

Desde 1939, al comienzo de la II Guerra Mundial, hasta 1955, Vietnam estaba totalmente apartada del resto del mundo. De 1955 a 1975, en plena guerra fría y bajo la agresión de Francia y Estados Unidos, las relaciones internacionales de la República Democrática de Vietnam se efectuaban exclusivamente con los países socialistas, sobre todo la Unión Soviética y China. Una vez alcanzada la independencia, para la mayoría del pueblo vietnamita, el capitalismo no podía menos de evocar un largo pasado colonial con todas sus injusticias y atrocidades y una reciente guerra sin piedad con la gran potencia capitalista de Estados Unidos de América; es pues natural 
que, alcanzada la independencia y bajo la hostilidad de los países del Sudeste Asiático, Vietnam buscase apoyo y ayuda en los países socialistas e intentase para su desarrollo, en oposición a la vía capitalista, una vía de desarrollo socialista.

En este período de gobierno socialista pueden distinguirse varias etapas:

- 1975-1976: Año de la reunificación político-administrativa y año de reencuentros en la población civil.

- 1978-1979. Crisis internacional, conflicto abierto con China y el Pot Pol de Camboya.

- 1980-1985. Primera tentativa de reformas económicas. Situación económica desastrosa. Descontento Popular.

- 1986-1988. EI VI Congreso Nacional del Partido Comunista de Vietnam introduce una nueva línea liberalizadora en el campo político, el famoso "Doi Moi".

- 1988-1990. Reformas económicas de importancia decisiva que afectan a la agricultura, las empresas privadas, las inversiones extranjeras y la gestión de las empresas estatales.

- 1990-1992. Primeros resultados de las reformas económicas.

El primer año después de terminada la guerra fue naturalmente un año de reconstrucción. La guerra que acababa de terminar dejaba 26 millones de cráteres causados por los 14 millones de toneladas de bombas y obuses lanzados por las tropas norteamericanas y sus aliados del sur, cientos de miles de minas antipersonales escondidas por toda la geografía del país, miles de hectáreas de campos y bosques defoliados y vueltos estériles por las armas químicas utilizadas, 10 millones de aldeanos expulsados de sus aldeas ( $3 / 4$ de las aldeas del sur y $2 / 3$ de las del norte), la totalidad de los puentes destruidos y las vías férreas cortadas, las principales ciudades del país arrasadas. La labor de reconstrucción con que se enfrentaba el nuevo gobierno único para todo el país y la Asamblea Nacional elegidos en abril de 1976 era enorme, reconstrucción de todo un aparato administrativo que integrase todo el país, el restablecimiento de comunicaciones por tren y carretera de las dos Vietnam y el reagrupamiento de centenares de miles de vietnamitas que habían quedado separados de sus familiares y amigos por el paralelo $17^{\circ}$ sin posibilidad al guna de contacto durante los 10 años de guerra con EE.UU., la reinserción en la vida civil de los miles de antiguos guerrilleros

\section{RFS}


que salían de las selvas o de las prisiones, así como la reincorporación a su antiguo modo de vida de los miles y miles de campesinos desplazados que deseaban volver a sus aldeas.

A todo ello tenía que añadirse el peligro de una guerra civil. Cerca de un millón de antiguos colaboradores con el régimen pro-americano de Saigón, soldados, oficiales, policías, y agentes de todo tipo, que tenían que aceptar vivir en un régimen comunista, los "Hoa" o comunidad china de Vietnam que contaba con unos 700.000 miembros en el barrio Cho Lon de Saigón y unos 200.000 en las provincias del norte, fronterizas con China, que se sentían más próximos a su país de origen y eterno enemigo de Vietnam, y los grupos étnicos minoritarios entre quienes primero los franceses y luego los norteamericanos habían encendido la llama del independentismo, todos ellos representaban un peligro serio a la construcción de un nuevo Vietnam unido. Además, una nueva amenaza surgía del exterior: en el este, el Pot Pol de Camboya, y en el norte, el eterno rival, China.

\subsection{El sistema de gobierno de Vietnam}

Según la constitución de 1992:

La República Socialista de Vietnam es un Estado del pueblo, desde el pueblo y para el pueblo. Todo el poder del Estado pertenece al pueblo y se basa en la unión de la clase trabajadora, los campesinos y la intelligentia. (art. 2)

El Partido Comunista de Vietnam, la vanguardia de la clase trabajadora, el fiel representante de los derechos e intereses de la clase trabajadora, y de toda la nación, actuando animada por la doctrina Marxista-Leninista y el pensamiento de Ho Chi Minh, es la fuerza que dirige el Estado y la sociedad.

Todas las organizaciones de Partidos trabajan dentro del marco de la Constitución y la ley.(art. 4)

Cada nacionalidad tiene el derecho de usar su propia lengua y sistema de escritura, a preservar su identidad nacional y a promover sus mejores costumbres, hábitos, tradiciones y cultura. (art. 5)

El pueblo usa el poder estatal a través de la Asamblea Nacional y el Consejo del Pueblo, que representan la voluntad y aspiraciones del pueblo, y son elegidos por él y son responsables ante él. 
El centralismo democrático es el principio que gobierna la organización y actividad de la Asamblea Nacional y el Consejo del Pueblo y todos los demás órganos del Estado. (art. 6)

Elecciones a la Asamblea Nacional y al Consejo del Pueblo se realizan según los principios de universalidad, igualdad, voto directo y sufragio universal. (art. 7)

El Frente de la Madre Patria de Vietnam y sus organizaciones constituyen la base política del poder del pueblo. (art. 9)

Los sindicatos, siendo las organizaciones socio-políticas de la clase trabajadora, unen sus esfuerzos a las organizaciones estatales económicas y sociales cuidánd ose y guardando los intereses y derechos de los cuadros, los trabajadores, los empleados y otra clase de gentetrabajadora; participan con el Estado en la administración de los asuntos sociales, en el control y supervisión de la actividad de los órganos estatales y otras organizaciones económicas. (art. 10)

La Asamblea Nacional es el máximo órgano de representación del pueblo y el único con poderes constitucionales y legislativos. Entre sus poderes están el poder elegir y destituir al Presidente, al Primer Ministro, al Presidente de la Asamblea General, al Presidente de la Corte Suprema, a los Ministros y a todos los demás cargos superiores del gobierno, así como abrogar cualquier documento escrito emitido por cualquier órgano del gobierno. La Asamblea Nacional tiene un mandato de cinco años pero en casos especiales, con la aprobación de dos tercios de sus miembros, puede éste prolongarse. La Asamblea Nacional se reúne normalmente dos veces al año para aprobar o desechar las proposiciones de ley presentadas por el Presidente, el Comité Permanente de la Asamblea, el Gobierno, el Frente de la Patria Vietnamita, etc. El órgano permanente de la Asamblea Nacional es el Comité Permanente de la misma compuesto por el Presidente y Vicepresidente de la Asamblea General y otros miembros elegidos por la misma Asamblea General. Su función principal es interpretar la Constitución y las leyes y en casos especiales autorizados, por la Asamblea General, promulgar sus propios Decretos Leyes. La Asamblea Nacional también nombra un Comité de Nacionalidades.

El J efe de Estado es el Presidente de la República, que es elegido por la Asamblea Nacional de entre sus miembros y ante la cual es responsable de sus actos y a la cual informa regularmente. El Presidente nombra a los 
Vicepresidentes y a los jueces del Tribunal Supremo. El Gobierno está compuesto por el Primer Ministro nombrado por la Asamblea Nacional, quien presenta a esta Asamblea para su aprobación el nombre de los que van a ser los distintos Ministros que compondrán el ejecutivo. El presidente del Comité Central del Frente Vietnamita de la Madre Patria, el Presidente de la Federación Vietnamita del Trabajo y otros representantes de organizaciones de masas pueden ser invitados a estar presentes en las sesiones del Gobierno cuando se trate de temas que les puedan interesar.

El gobierno local del país se compone de provincias, distritos, comunas y pequeños municipios. El People's Council (Consejo del Pueblo) es el órgano local del gobierno y, elegido por la población local, representa sus deseos y aspiraciones y está dirigido por un Presidente. El People's Council nombra un órgano ejecutivo que es el People's Conmmittee (Comité del Pueblo) que es el órgano local de la administración del Estado. El Consejo del Pueblo y el Comité del Pueblo informarán regularmente al Frente Vietnamita de la Madre Patria y otras organizaciones de masas sobre la situación local y escucharán las opiniones y propuestas presentadas por estas organizaciones para el desarrollo local.

\section{Una nueva economía de mercado}

\subsection{Autocrítica y Renovación ("Doi Moi”)}

En 1976 se reunió el IV Congreso del Partido de los Trabajadores de Vietnam tomando el nuevo nombre de Partido Comunista de Vietnam que siguió en su planificación económica una línea acorde con la más pura ortodoxia marxista-leninista tal como la había aplicado la Unión Soviética en los años cuarenta. Se movilizaron to dos los movimientos de masas-mujeres, jóvenes y sindicatos- para denunciar y eliminar todo vestigio de comercio privado, transformar las fábricas capitalistas de Saigón en empresas del Estado y forzar a todos los campesinos a unirse en cooperativas estatales, y grandes granjas del estado fueron creadas para servir como unidades de vanguardia en la agricultura. Pero pronto se dieron cuenta que esta línea no llevaría al desarrollo del país. Como puede leerse en la historia de Vietnam del Prof. Naguyen Khac Vien, "este ideal dio por resultado la puesta en pie de un enorme aparato burocrático que todo lo decidía, hasta los menores detalles, una centralización hasta el extremo, que no dejaba ninguna inicia- 
tiva ni a las direcciones de provincias, ni a las de las empresas ni a los individuos, cada unidad, cada individuo se contentaba con esperar que las instancias centrales le suministrasen los subsidios financieros, las materias primas, los índices de producción a cumplir, decidían los salarios y fijaban los precios"3 y, continúa el mismo autor, "siguiendo fielmente el modelo de desarrollo soviético, no podían más que fortalecer el aislamiento internacional del país y encerrarse en un cuadro ideológico rígido poco propicio a los cambios propio de una ortodoxia devenida a veces sofocante". La ayuda importante que Vietnam recibía de la Unión Soviética y China y la situación constante de guerra o peligro de ella "había ocultado la necesidad de volverse del lado del mercado capitalista mundial. Y el atraso en el conocimiento del mercado mundial había constituido un freno muy importantepara el desarrollo económico del país"4.

El año de 1978 se inició con una profunda crisis política y económica en Vietnam. Por una parte, mientras las fuerzas del Pol Pot camboyano multiplicaban sus ataques a lo largo de la frontera vietnamita, China inició una feroz campaña anti vietnamita apoyada en el interior del país por la numerosa comunidad de los Hoan, vietnamitas de origen chino; por otra parte, los numerosos tifones del verano de de 1978 causaron la pérdida de más de 3 millones de toneladas de arroz afectando a más de 6 millones de personas, y llevaron al país a una situación económica desastrosa que forzó a los gobernantes a admitir que la grave situación económica no podía explicarse sólo por las presiones políticas venidas del exterior, sino que su inexperiencia en materia de gestión económica había tenido consecuencias desastrosas.

En agosto de 1979, el Pleno del Comité Central del Partido Comunista de Vietnam tuvo que admitir el fracaso de sus políticas económicas y tomar una serie de medidas tendentes a asegurar los intereses de las explotaciones familiares individuales y de los trabajadores, hasta entonces sacrificados en beneficio de las empresas del Estado y la colectividad y, al mismo tiempo, se hizo una severa crítica de la corrupción en las filas del aparato del Estado y del Partido. En 1980 se adoptó una nueva Constitución pero, como dice el autor arriba mencionado "las nociones de derechos del ciudadano, de democracia, de legalidad eran todavía las abstracciones a menudo incom-

3 Nguyen Khac Vien (1997), p. 501.

4 Idem, p. 499.

RFS 
prendidas tanto por parte de los cuadros dirigentes de diversos escalones como por parte del pueblo en cuanto a la situación económica del país" 5 .

En 1982 el V Congreso del Partido Comunista aprobó una importante

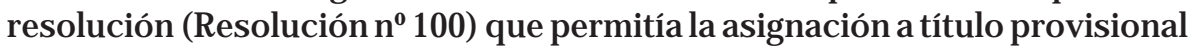
de parcelas familiares a los hogares campesinos, dán doles una cierta libertad de maniobra en cuanto al cultivo así como a la venta de los productos agrícolas. Aunque estas medidas mejoraron un poco la producción agraria, no sirvieron para resolver los múltiples problemas con los que se enfrentaba el país: "los campesinos se desinteresaban de las actividades de las cooperativas estatales, los intelectuales no podían ejercer sus funciones mientras que se formaba rápidamente una clase de nuevos ricos. El Gobierno, novicio en el terreno económico, no podía resolver los problemas, la crisis tomaba un carácter social, zapando los valores fundamentales de la sociedad, creando poco a poco un estado de anomía"6. Para hacer frente a esta situación e influenciados por las nuevas ideas Ilegadas de la Unión Soviética como eran la perestroika y la glasnot, y las tesis del XXVII Congreso del Partido Comunista de la Unión Soviética, se convocó en 1986 un nuevo Congreso (VIํ) del Partido Comunista que tenía que introducir reformas revolucionarias en todo el sistema económico del país con el famoso eslogan "Doi Moi" (Renovación). El 15 de diciembre de 1986 se abría el VI Congreso con este objetivo, expresado en el Informe Político: "el congreso debe marcar un jalón crucial por la renovación de nuestro sistema de pensamiento, nuestro estilo de trabajo, de nuestras modalidades de organización... Nuestro Partido debe mirar a la verdad y decir toda la verdad"7. El Informe reconocía errores graves y prolongados en sus políticas concretas, errores debidos a subjetivismo, al voluntarismo, los errores ideológicos, los errores de las políticas de organización. "Hasta hoy el mecanismo de gestión centralizada burocrática descansando sobre las generalizadas subvenciones del Estado no ha sido liquidado en lo esencial... El Estado del centralismo burocrático es grave, mientras las manifestaciones de indisciplina son bastantes extendidas... Los gastos del presupuesto son hechos en gran parte a título de subvenciones y durante un largo período han rebasado los ingresos. La utilización de los préstamos y ayudas es poco rentable. Todo esto ha sido el origen del déficit

\footnotetext{
5 Idem, p. 506.

6 Idem, p. 509.

7 Informe Político del VI Congreso Nacional del Partido Comunista de Vietnam.
} 
presupuestario y constituye la causa directa de una grave inflación"8.

En las Conclusiones del Congreso se aprobó, primero, la necesidad de mantener, junto con las iniciativas económicas del Estado, un sector de economía privada, individual y capitalista, con los mismos derechos que el sector del Estado; segundo, la gestión de todos los sectores económicos, incluyendo el sector del Estado, no debía basarse más en criterios puramente políticos, sino en los criterios de rentabilidad, y la movilización política e ideológica debía ceder el puesto a los incentivos materiales; tercero, el dogma de la prioridad de la industria pesada debía ser rechazado y se debía dar prioridad a la industria ligera, la industria artesanal, y la producción de bienes de consumo debía tomar prioridad. En aplicación de esta nueva política económica en los años siguientes se tomaron medidas de vital importancia para la economía del país: se autorizó de manera muy liberal a las firmas extranjeras a invertir en Vietnam y se perfeccionó la antigua Resolución 100 - sobre asignación de lotes de tierra a las familias campesinas en el sentido de dar una plena libertad de explotación y comercialización de sus productos.

En 1989 hubo un retroceso ideológico ante el posible peligro de que la apertura económica llevase a una desviación de las tesis políticas más ortodoxas. El Partido reafirmó con vigor su fidelidad al marxismo-leninismo, su voluntad de construir el socialismo según la "vía" abierta por Ho Chi Minh, su oposición a todo pluralismo político y la defensa de la economía de mercado pero controlada por el Estado. Todas estas tesis se reafirmaron en el VII Congreso del Partido, celebrado en 1991, en el que se enumeraron los males que empezaban a amenazar al país: corrupción de cuadros, contrabando, fraude fiscal, invasión de mercancías extranjeras, escándalos financieros, aumento de la criminalidad y peligro de drogas. El Informe del Comité Central del Partido sobre los Documentos del VII Congreso Nacional ${ }^{9}$ reafirmaba que la tierra era del Estado pero era confiada a los campesinos para una larga utilización, pero al mismo tiempo creía que no era posible la total privatización de la tierra pues esto llevaría a grandes diferencias de clase.

La economía individual debía poder ampliar sus negocios, existir independientemente o participar en las diversas formas de cooperativas o aliarse con

8 Idem, p. 523.

9 Informe del Comité Central del Partido sobre los Documentos del VII Congreso Nacional en Ngueyn Khak Vien (1997), pp. 537 y ss. 
las grandes firmas bajo diversas formas. La economía capitalista privada, por consiguiente, tenía que ser autorizada en las ramas útiles a la economía nacional y al bienestar social, y fijadas por la ley. Para potenciar la economía de varios componentes hacía falta proseguir la liquidación del mecanismo de centralismo burocrático asentado en subvenciones del Estado generalizadas y pasar al mecanismo de mercado con la gestión del Estado por intermediación de la ley, los planes y las políticas.

En medio del debate económico, el Comité Central del Partido hizo unas interesantes reflexiones sobre la democracia y cómo esta debía ser entendida. Algunos sostienen, dijeron, que solamente hay democracia con la existencia de un mecanismo político pluralista y de partidos de oposición. Que haya democracia o no, esto no depende del hecho que el régimen sea mono o pluripartidista. En el antiguo Saigón donde había decenas de partidos nadie pensaba que la población gozaba de mucha democracia. "El Partido, afirmaron rotundamente, hace del marxismo-leninismo y del pensamiento de Ho Chi Minh el fundamento ideológico, la brújula para sus actos... El pensamiento de Ho Chi Minh es justamente el resultado de la aplicación creadora del marxismo-leninismo en las condiciones concretas de nuestro país"10.

Para liberar y hacer florecer las potencialidades de la producción en la sociedad, terminaban diciendo, era absolutamente justo y necesario pasar de una economía pesadamente autárquica, con un mecanismo de gestión centralizada burocrática basado sobre las subvenciones del Estado, a una economía de mercado de muchos componentes que se moviese según el mecanismo de mercado puesto bajo la gestión del Estado.

En 1992 la Asamblea Nacional eligió un nuevo gobierno, y unánimemente lo incitó a llevar a cabo una lucha resuelta contra la corrupción. Esta misma Asamblea Nacional se puso como tareas para el año siguiente, entre otras:

a) Para desarrollar sólidamente la producción agrícola, proceder lo más pronto posible al otorgamiento de las tierras y arrozales a los agricultores y resolver activamente los conflictos de los agricultores acerca del problema de la tierra. En la agricultura el gobierno debe invertir en nuevas infraestructuras, facilitar el crédito, ayudar en la introducción de nuevas tecnologías, desarrollar la industria de procesamiento y fomentar la salida de los productos agrarios a los mercados nacionales e internacionales, ayudar a mejorar la gestión de las cooperativas.

10 Idem, p. 543. 
b) Reorganizar las empresas del Estado, disolviendo las que trabajan con pérdidas. Promover la constitución de empresas por acciones, cambiar la forma de propiedad para las empresas que no necesitan ser propiedades del Estado, estudiar y promulgar las políticas que miren a movilizar los componentes económicos no estatales.

c) Buscar capitales de préstamo en el extranjero o inversión del capital global por el extranjero para la construcción de obras clave y de infraestructura; crear las condiciones favorables para atraer la inversión extranjera.

d) Ampliar el mercado de exportación y luchar contra el contrabando, al mismo tiempo que se eleva la capacidad competitiva de los productos nacionales.

e) Erradicar poco a poco el igualitarismo en las escalas y escalones salariales, fijando el régimen de salarios según los resultados del trabajo, garantizando las necesidades esenciales de la vida del asalariado.

f) Aplicar beneficiosamente las nuevas tecnologías, protegiendo el medio ecológico y explotando de forma racional los recursos naturales. Finalmente, promover las actividades de investigación, especialmente en materia de gestión económica en la economía de mercado.

En 1991 el Informe del comité Central del Partido sobre los Documentos del VII Congreso Nacional decía: "Para alcanzar nuestros objetivos, preconizamos perseverar la política de una economía de muchos componentes y siguiendo la orientación socialista. Todos los ciudadanos son libres de dedicarse a cualquier trabajo según la ley: sus derechos de propiedad y sus ingresos legales son protegidos. Las formas de propiedad pueden asociarse y solaparse para formar empresas multiformes. Las empresas son iguales ante la ley sin distinción de relaciones de propiedad y autónomas en los negocios, la cooperación y la competencia... Es un error mantener y desarrollar de manera generalizada la economía de Estado y de prolongar el régimen de subvenciones del Estado generalizadas"11.

11 Idem, p. 538. 


\subsection{Economía en la Constitución de 1992}

El sistema económico según la Constitución de 1992 es el siguiente:

El Estado promueve una economía mixta (multi-componente) de bienes según los mecanismos del mercado y bajo la gestión del Estado, siguiendo la orientación socialista. Esta estructura económica mixta (multi-componente) con varias formas de organizar la producción y el comercio está basada en un sistema de propiedad de todo el pueblo, de colectividades, y de individuos privados, cuyo fundamento es la propiedad por todo el pueblo y las colectividades. (art. 15)

El objetivo económico del Estado es hacer al pueblo rico y a la nación fuerte... desarrollando todas las posibilidades latentes en los distintos componentes de la economía: el sector estatal, el sector colectivo, el sector de los individuos privados, el sector del capitalismo privado, y el sector del capitalismo de Estado en sus diversas formas. (art. 16)

El Estado gestiona toda la tierra según los planes y la ley, y garantiza que su uso será conforme a los objetivos fijad os y con una productividad efectiva.

El Estado confiará la tierra a organizaciones e individuos privados para su uso estable y permanente. Estas organizaciones e individuos son responsables de la protección, enriquecimiento, explotación racional y uso económico de estas tierras; ellos pueden transferir, según determine la ley, el uso de la tierra confiada a ellos por el Estado. (art. 18)

\subsection{Algunos datos económicos}

Los objetivos fijados por este Plan Quinquenal 1991-1995, el primero después de la Doi Moi fueron superados con creces. EI PIB se había fijado que subiese entre un 5,5 y un 6,6\% y subió en una media anual del $8,2 \%$. En agricultura y pesca se habían fijado unos incremento del 3,4\% y llegaron al $4,3 \%$. Pero el éxito más extraordinario fue que la producción agraria no sólo fue capaz de cubrir el total de las necesidades alimenticias de la población, sino que se pudo exportar un importante excedente agrícola, creando así las posibilidades de poner las bases para la industrialización del país y la transformación de las zonas rurales. En 1995 la producción de arroz llegó a 27,5 millones de toneladas y al año siguiente a 29 millones. De una posición anterior en la que Vietnam se veía forzada a importar anualmente cerca de 1 millón de toneladas de arroz, Vietnam se convirtió en el tercer mayor exportador de arroz con cerca de 3 millones de toneladas anuales.

\section{ESTUDIOS}




\section{CUADRO 1}

\section{Objetivos alcanzados y propuestos para el futuro}

\begin{tabular}{|c|c|c|c|c|}
\hline SECTORES & \begin{tabular}{|c|} 
Objetivos \\
alcanzados \\
$2000^{(1)(3)}$
\end{tabular} & \begin{tabular}{|c|} 
Objetivos \\
alcanzados \\
$2001^{(1)}$
\end{tabular} & $\begin{array}{c}\text { Objetivos } \\
\text { para } \\
2002^{(2)}\end{array}$ & $\begin{array}{l}\text { Objetivos para } \\
\text { Plan Quinquenal } \\
\text { 2002-2005 (2) }\end{array}$ \\
\hline Incremento PIB & $6,7 \%$ & $7,5 \%$ & $7,3 \%$ & $7,5 \%$ anual \\
\hline $\begin{array}{l}\text { Crecimiento valor producción } \\
\text { agro- forestal y pesca }\end{array}$ & $4,9 \%$ & $4,5 \%$ & 4,2 & $4,8 \%$ anual \\
\hline $\begin{array}{l}\text { Producción alimenticia (arroz, } \\
\text { millones toneladas) }\end{array}$ & 35,7 & & & \\
\hline Crecimiento producción industrial & $10,5 \%$ & $14,55 \%$ & $14,5 \%$ & $7,5 \%$ anual \\
\hline Crecimiento producción servicios & $6,0 \%$ & $7,5 \%$ & $7,0 \%$ & \\
\hline Crecimiento exportaciones & $24,0 \%$ & $16 \%$ & $13 \%$ & $14,5 \%$ anual \\
\hline $\begin{array}{l}\text { Crecimiento empleo (millones } \\
\text { nuevos puestos de trabajo) }\end{array}$ & 1,3 & 1,4 & 1,4 & 1,5 millones /anuales \\
\hline Crecimiento Formación Profesional & 790.000 & 840.000 & 1.000 .000 & \\
\hline Reducción índice de natalidad & $0,05 \%$ & $0,05 \%$ & $0,04 \%$ & $\begin{array}{c}0,05 \% \\
\text { objetivo: } 1,2 \% \text { anual }\end{array}$ \\
\hline Reducción familias pobres & $11 \%$ & $10 \%$ & $15 \%$ & \\
\hline
\end{tabular}

Fuentes: (1) Publicación Oficial. "Vietnam 2000-2001”. Editorial Thê Giöi. Hanoi. 2001, p. 6 y 34.

(2) Publicación Oficial "Vietnam 2001-2002". Thê Giöi Publishers. Hanoi. 2002, p. 98 y 107.

(3) Responsable, CátVân Thành.Central Managementfor Economic Management “Vietnam's Economy In 2000". Statistical Publishing House. Hanoi. 2001, pp. 10 y ss.

La industria y la construcción, que al iniciarse este Plan Quinquenal suponía el $22,7 \%$ del PIB al final del Plan habían llegado al $29 \%$ y al año siguiente al $31 \%$. Durante este Plan se crearon nuevas instituciones financieras: cuatro bancos del Estado, 60 bancos domésticos y 4 bancos mixtos, así como 11 bancos subsidiarios y 52 oficinas representativas de bancos extranjeros ${ }^{12}$.

12 Fuente de datos Daâng Dùc Dam (1997).

\section{RFS}




\section{GRÁFICO 1}

Distribución del PIB por sectores de producción (en \%)

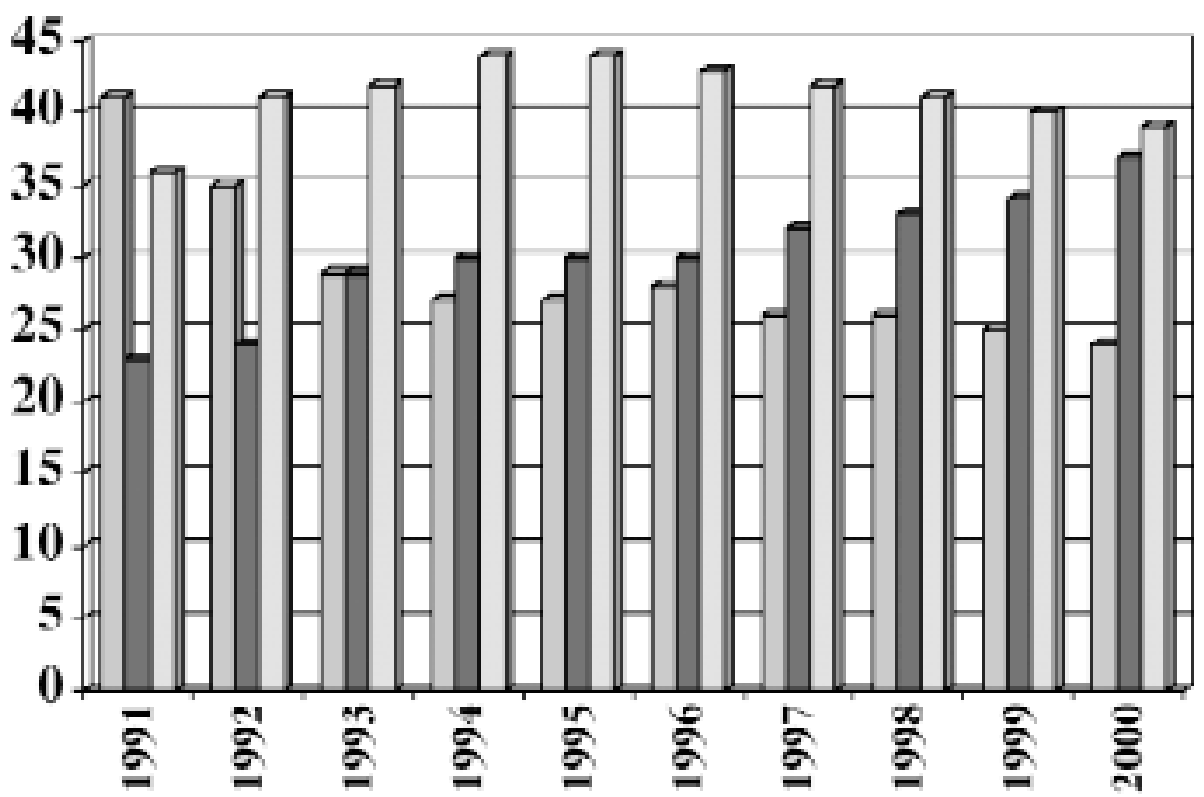

\section{$\square$ Agricultura $\square$ Ind.+Const $\square$ Servicios}

Como muestra el gráfico $1^{13}$, en los últimos diez años la distribución del PIB por sectores de producción ha seguido la línea de toda economía en desarroIlo: disminución del sector agrario y aumento de los otros dos sectores, industria con construcción y servicios. En 1991 la agricultura contribuía con un $40,5 \%$ al PIB y en el 2000 su contribución había bajado a un $24 \%$. Por el contrario, en estos mismos diez años, la contribución de la industria y construcción al PIB había subido del 23,5\% al 37\% y la del sector servicios del $36 \%$ al $39 \%$. La débil subida del sector servicios nos muestra que hoy Vietnam todavía está inmerso en un proceso de industrialización.

En el gráfico 2 se observan las mismas tendencias, aunque menos pronunciadas en la distribución de la mano de obra por sectores de producción.

13 CIEM (2001), p. 110. 
GRÁFICO 2

Distribucion de la mano de obra por sectores de producción (en \%)

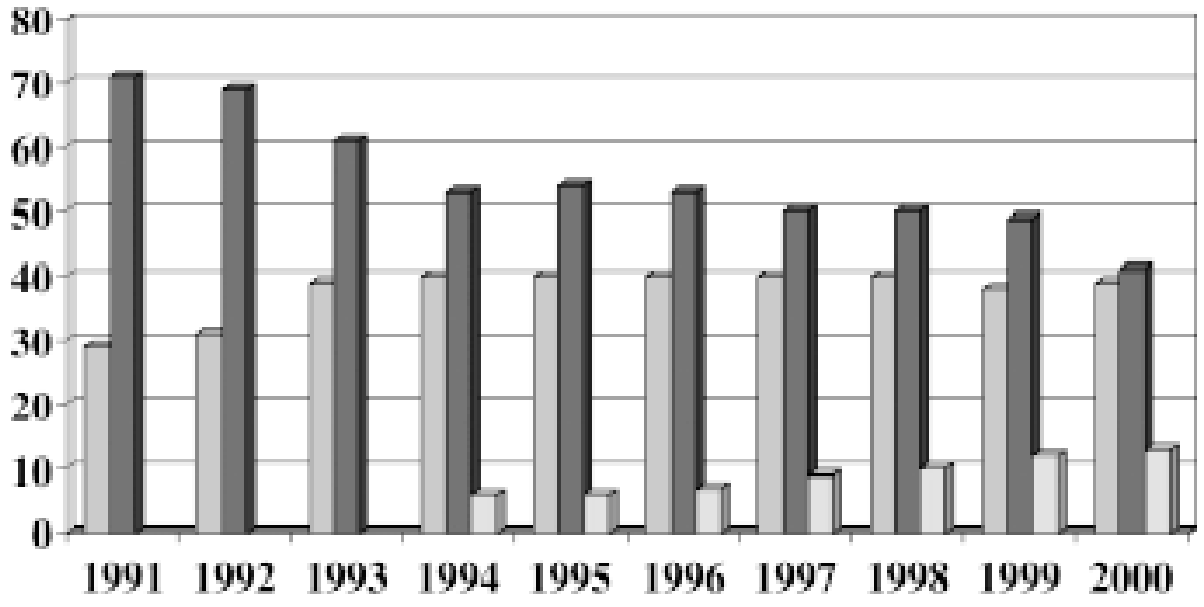

Estado $\square$ Privado $\square$ Extranjero

GRÁFICO 3

Distribución del PIB por tipos de empresa (en \%)

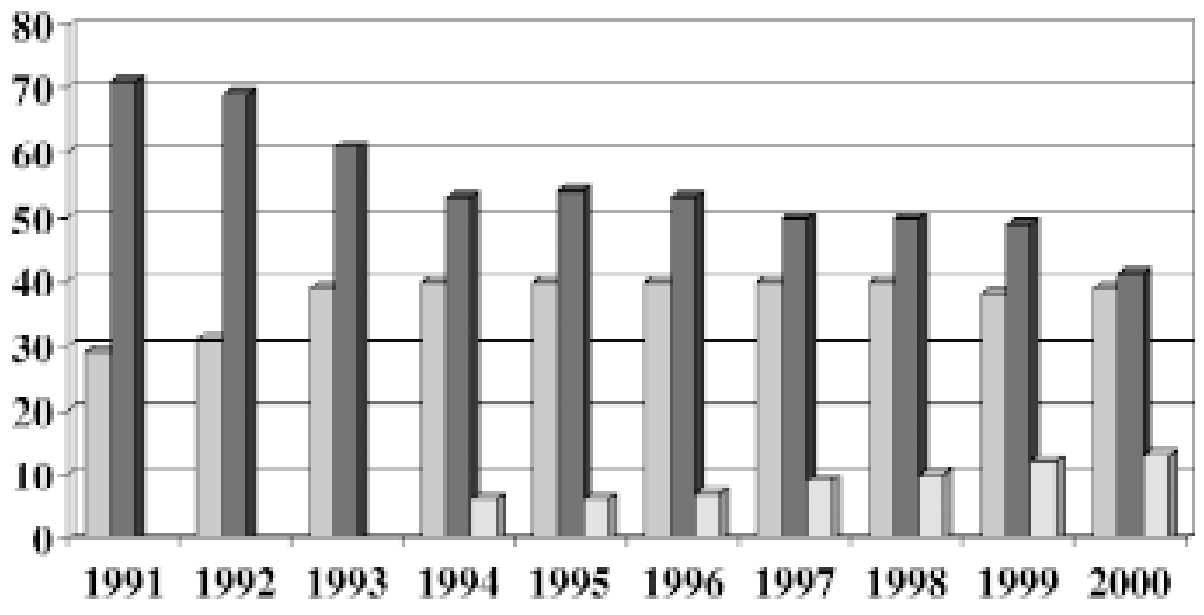

Lstado $\square$ Privado $\square$ Extranjero 
Mientras en el año 1991 las cifras eran: para la agricultura el 73,5\%, para la industria y construcción el $12,4 \%$ y para los servicios el $14,3 \%$, diez años más tarde estas cifras eran: $62,6 \%$ agricultura, $13,6 \%$ industria y construcción y $24,3 \%$ servicios.

Otra tendencia importante a tener en cuenta es el crecimiento de la contribución al PIB de las empresas con inversiones extranjeras (gráfico 3). En esta última década, excepto en los dos primeros años, la contribución al PIB de las empresas estatales se ha mantenido al rededor de un $40 \%$, mientras que la contribución de las empresas nacionales no-estatales ha disminuido considerablemente, del $71 \%$ al $48 \%$, a favor de las empresas con capital extranjero cuya contribución al PIB ha subido del $0 \%$ en los tres primeros años de la década, al 6,4\% en 1994, cuando se empezó a liberalizar la economía, experimentando desde entonces un crecimiento constante de $6,3 \%, 7,4 \%, 9 \%, 10 \%, 12 \%$, y $13,3 \%$ en el año 2000.

\section{LA NUEVA EMPRESA}

\subsection{Necesidad de cambio}

En 1985 la mala situación económica del país iniciada en 1978 parecía cada día agravarse más: una balanza comercial claramente deficitaria, una inflación galopante, unos salarios que no cubrían más que un tercio de los gastos mínimos de una familia obrera, una deuda pública en constante aumento. Para poder salir de la situación catastrófica en la que se encontraba sumido el país, el 10 de julio de 1986 el gobierno adoptó, como ya hemos visto, la política del "Doi Moi" (Renovación) y el 15 de diciembre del mismo año se abrió el VI Congreso Nacional del Partido Comunista, con el propósito de dar un vuelco de ciento ochenta grados a toda la política económica del país.

Pero el Gobierno vietnamita se dio cuenta muy pronto de que para llevar a cabo las reformas al sistema económico del país que se proponía, era esencial reformar todo el marco jurídico de la empresa y dar a ésta el lugar que le correspondía en una econo mía de mercado. Y, con la típica autocrítica que ha caracterizado las acciones de los líderes de aquel país en los últimos años, empezaron a repensar el lugar que debía ocupar la empresa privada. El Informe político del VI Congreso Nacional del Partido Comunista reconoció ante todo la falta de conocimientos de una moderna gestión empresarial: 
"Nos hemos inclinado a organizar grandes cooperativas -decía el Informesin tener en cuenta las posibilidades en materia de equipamiento técnicos, del nivel de gestión y de la capacidad de los cuadros... se ha subrayado el cambio de la relación de propiedad de los medios de producción sin pararse a resolver los problemas relativos a la organización de la gestión y el régimen de repartición de los productos"14. Está claro, continuaba el Informe que "todavía nos faltan conocimientos y experiencias en materia de gestión, y además hemos descuidado aprovechar las experiencias necesarias. No hemos tenido todavía una política financiera fundamental ligada estrechamente a una política correcta relativa a los precios, la moneda, el crédito y los salarios. El Estado no ha racionalizado las rentas de los comerciantes privados".

El Informe veía la necesidad de apoyar y fomentar la economía familiar a través de sus propios esfuerzos empresariales, y reconocía que la economía familiar ocupaba un puesto importante en la economía y estaba dotada de ricas posibilidades y, por tanto, debía ser estimulada y ayudada a desarrollarse, y debía establecerse una ligazón estrecha con el Estado y la colectividad, las familias de los obreros, funcionarios y cooperativistas, de manera que pudiesen ampliar la producción por su propio trabajo, explotar diversas ramas y profesiones en conformidad con las leyes y las políticas del Estado. Los pequeños comerciantes debían ser ayudados a modernizar sus sistemas de producción y de creación de servicios. Se reconocía así mismo que el Estado necesitaba a la pequeña industria productora de mercancías en el período de transición al socialismo. Era pues necesario evitar los prejuicios, las medidas de discriminación y las molestias para con los trabajadores individuales que no querían to davía adherirse a las organizaciones económicas colectivas o los que pedían retirarse de ellas.

Este Congreso propuso que el Estado autorizase a los pequeños capitalistas a utilizar sus capitales y sus conocimientos en materia técnica y gestión para organizar la producción y la explotación en un cierto número de ramas y profesiones del ámbito de la producción y de los servicios donde esto resultase necesario en el país entero. Es cierto, afirmaba el Informe del Partido, que el Estado tiene políticas propias (en materia de inversiones, impuestos, créditos...) privilegiando en el plano económico el componente socialista; pero era necesario, decía, aplicar el principio de igualdad en el

14 Informe Político del VI Congreso Nacional del Partido Comunista de Vietnam. 15 diciembre, 1986. 
plano jurídico. "Todos los que producen bienes y hacen cosas útiles a la sociedad, que cumplen completamente sus obligaciones, respetan correctamente las leyes y las políticas, tienen derecho al respeto, el disfrute de los ingresos correspondientes a los resultados de su trabajo y su explotación legal".

Luego el Informe Político entraba en una de las más duras autocríticas jamás realizada por un partido comunista: "El mecanismo de gestión según el centralismo burocrático -decía el Informe- basado en subvenciones del Estado generalizadas, sin crear desde hace muchos años una fuerza motriz de desarrollo, ha debilitado la economía socialista, limitando la utilización y la transformación de los otros componentes económicos, obstaculizando la producción, bajando la productividad, la calidad y la eficacia, sembrando la confusión en la circulación y la distribución de los productos y dando nacimiento a numerosos fenómenos negativos en la sociedad." Y continuaba, "Ias unidades de base no tienen ninguna autonomía y al mismo tiempo, no están ligadas en cuanto al tiempo y a las responsabilidades a los resultados de sus actividades. Este mecanismo no tiene suficientemente en cuenta la relación mercancía-moneda ni la rentabilidad económica, lo que conduce a un método de gestión y planificación basado sobre un régimen de suministros y entregas esencialmente en especies, donde el cálculo económico es pura forma, donde las responsabilidades y los intereses materiales no están ligados a la eficacia de la utilización de los fondos, los recursos, bienes materiales y mano de obra, y donde la remuneración no tiene en cuenta ni la cantidad ni la calidad del trabajo contribuido... Este antiguo mecanismo está ligado a un pensamiento económico fundado sobre concepciones simplistas del socialismo y pesadamente cargadas de subjetivismo y voluntarismo". Esta parte del Informe terminaba afirmando que el Estado debía controlar y dirigir las empresas y las unidades de producción y explotación pertenecientes a diversos componentes económicos sólo por medio de la ley, las políticas económicas y las políticas en materia de progreso científicotécnico, mucho más que interviniendo en sus actividades de producción y explotación. El Comité Central de Planificación debía descargarse de una parte de los asuntos corrientes y debía concentrarse mucho más en el estudio de las estrategias socio-económicas, la elaboración de los planes a largo y medio plazos, el trabajo de equilibrio del conjunto de la economía, la elaboración de las políticas, las leyes y los reglamentos económicos. "La gestión del país -terminaba diciendo el Informe- debe hacerse por medio de la ley y no únicamente por preceptos morales, pues la ley debe ser escrupu-

\section{ESTUDIOS}


losamente observada por todos ya que todos son iguales ante ella"15.

Con este espíritu de renovación se aprobó el 15 de abril de 1992 la nueva Constitución en la que se reflejan los mismos criterios expuestos por el VI Congreso del PC sobre la libertad de empresa:

En los sectores de individuos privados y capitalismo privado, la gente podrá adoptar su propia manera de organizar la producción y el comercio; se pueden establecer empresas de alcance ilimitado en áreas de actividad que son beneficiosas para el país y el pueblo. (art. 21)

La propiedad legal de los individuos y las organizaciones no será nacionalizada. En caso de absoluta necesidad... el Estado puede obligar a vender o puede requisar parte de la propiedad de individuos y organizaciones, siempre con la adecuada compensación según los precios corrientes del mercado. (art. 22)

El Estado anima a empresas extranjeras e individuos a invertir capitales y tecnología en Vietnam... Las empresas con inversiones extranjeras no serán nacionalizadas. (art. 23)

Las Resoluciones adoptadas por la Asamblea Nacional de la República de Vietnam en diciembre de 1993 insistían en las mismas ideas de una renovación política estrechamente ligada a una renovación económica y se fijaba las siguientes tareas para los próximos años: ${ }^{16}$

\footnotetext{
“- Para desarrollar la producción agrícola, proceder lo más pronto posible al otorgamiento de las tierras y arrozales a los agricultores y resolver activamente los conflictos entre agricultores acerca del problema de las tierras.

- Reorganizar las empresas del Estado, disolver las que trabajan con pérdidas. Promover la experimentación de la constitución de sociedades de acciones. Cambiar la forma de propiedad para con las empresas que no tienen necesidad de continuar siendo propiedad del Estado. Estudiar y promulgar las políticas encaminadas a movilizar a los componentes económicos no estatales.

- Buscar capitales de préstamo del extranjero, y fomentar las formas de «jointventures» en cooperación con el extranjero.

- Realizar el nuevo régimen de salarios a fin de erradicar poco a poco el igualitarismo en las escalas y escalones salariales. Fijar el régimen de salarios según los resultados del trabajo, garantizar las necesidades esenciales de la vida de los asalariados"17.

16 Resoluciones adoptadas el 23 de diciembre de 1992 por la Asamblea Nacional de la República Socialista de Vietnam, IX legislatura, 2ª sesión. Citado en Nguyen Khac Vien (1997), p. 548.
}

15 Idem, p. 535

17 Idem, pp. 551-555. 


\subsection{Un nuevo marco jurídico de la empresa}

Poner en práctica todas estas ideas de renovación económica necesitaba, naturalmente, de una serie de instrumentos legales que debían todavía crearse y esto suponía cambios profundos ideológicos. En un país comunista, es obvio que no puede existir una diferencia entre Derecho Publico y Derecho Privado, como tampoco entre legislación civil y legislación económica comercial. Todas las relaciones son públicas y la legislación económica sólo hace referencia a las relaciones entre unidades económicas estatales y las de éstas con la administración pública. Hasta la división del país en 1954, Vietnam aceptó la legislación civil y comercial de la metrópolis francesa, pero con la Constitución de 1959 Vietnam se adentró más en el bloque de países socialistas imitando mucho la legislación civil y comercial china. Terminada la guerra en 1975, la Asamblea Nacional de la reunificada Vietnam aprobó la tercera Constitución aceptando de pleno el modelo de economía planificada socialista. Pero en 1986, como ya hemos visto, Vietnam se embarcó en una política de renovación profunda cuyo objetivo era establecer un Estado de derecho y transformar la economía planificada, en una economía de mercado, para lo cual necesitaba de un nuevo marco institucional cuyas fuerzas motoras fuesen las fuerzas del mercado. Así la nueva Constitución creó la base legal para un nuevo sistema económico, reconociendo una vía legal a las actividades empresariales privadas. "El objetivo de toda actividad económica, según esta Constitución, es desarrollar la prosperidad del pueblo y mejor satisfacer sus necesidades materiales y espirituales". La nueva Constitución intenta desarrollar, como hemos visto, un sistema económico "multi-sectorial", proteger la libertad de empresa privada y mantener intacta la "orientación socialista de la economía". En estecontexto constitucional se aprobaron una serie de leyes indispensables para una economía de mercado:

- Un nuevo Código Civil de Oct. 28, 1995.

- Ley de Compañías y Ley de Empresas Privadas de diciembre de 1990 y enmendada en julio de 1944. Sustituidas por la Ley de Empresa de mayo de 1999.

- Ley de Empresas estatales de Abril de 1995.

- Ley de Quiebras Empresariales de 1993.

- Ley del Suelo aprobada en 1993 y enmendada en 1998.

- Ley de Inversiones Extranjeras que ha sufrido varias enmiendas hasta la actual ley de junio de 2000. 
- Código de Trabajo de junio de 1993.

- Ley de Promoción de la Inversión Doméstica de 1994 y enmendada en 1998.

- Código de Comercio de 1997.

- Ley de Seguros empresariales de diciembre de 2000.

- Ley de Cooperativas de marzo de 2000.

A todas estas leyes básicas deberían añadirse las leyes sobre impuestos, propiedad intelectual, protección del medioambiente, protección del consumidor, banca y finanzas, Bolsa y Cambio, antimonopolio, etc.

Todo este cuerpo legislativo nuevo ha transformado la inicial legislación económica en una verdadera legislación de empresa con distintas formas de propiedad que son, sin embargo, iguales ante la ley. Esta nueva legislación asegura la libertad de establecer una empresa y llevar a cabo todas sus actividades empresariales; derecho a entrar en cualquier tipo de contrato de empleo de personal asalariado, contratos de cooperación con individuos u organizaciones extranjeras, derecho a acumular y disponer libremente de la propiedad adquirida legalmente; regulación del intervencionismo estatal, etc.

Una economía de mercado para poderse desarrollar necesita de unos condicionantes esenciales que la nueva legislación económica (comercial, mercantil) de Vietnam intenta asegurar. Una economía de mercado no puede existir sin algún tipo de derecho a la propiedad privada que genere la iniciativa, la competencia y la eficiencia tecnológica. Los legisladores vietnamitas han reconocido la necesidad de la economía de mercado antes que la necesidad de un derecho absoluto de propiedad. La tierra sigue siendo propiedad del Estado y las empresas públicas siguen ocupando un lugar preferente en la economía del país, sin embargo, todo ciudadano tiene derecho a organizar y llevar una empresa, a escoger una profesión, a contratar libremente y a utilizar su propiedad según dicta la ley. La nueva legislación, como declaró el VIII Congreso Nacional del Partido Comunista, también intenta fomentar una "justa, legal y civilizada competencia entre empresas"18, y para ello se asegura legalmente la igualdad de todas las empresas, públicas y privadas, nacionales y extranjeras, ante la ley.

18 Pham Duy Nghîa (2002), p. 67. 
Finalmente este establecimiento de una economía de mercado ha exigido a los gobernantes vietnamitas fo mentar el proceso de integración del país en los organismos económicos regionales e internacionales. Abiertos los mercados nacionales al comercio internacional y a las inversiones extranjeras, Vietnam ha intentado entrar en toda clase de convenios comerciales bi- y multi-laterales. En 1994 Vietnam adquirió el status de observador en la OMC y al año siguiente presentó su solicitud formal de admisión, todavía pendiente de resolución. En 1995 entró como miembro en la Asociación de Naciones del Sureste Asiático (ASEAN) y dos años más tarde en la Organización de Cooperación Económica del Asia del Pacífico (APEC). Además, Vietnam tiene Convenios de Colaboración con más de 60 países, uno de los últimos fue el firmado con EE.UU. en julio de 2002.

\section{Unos derechos civiles en crecimiento}

En este apartado analizamos los Derechos Fundamentales reconocidos por la Constitución vietnamita de 1992 haciendo especial hincapié en el problema de la libertad religiosa en este país.

La constitución reconoce to dos los Derechos Fundamentales de cualquier Estado moderno. El problema está, como siempre, en las interpretaciones que se den al texto constitucional y a las leyes que desarrollan estos Derechos Fundamentales. "Conviene no olvidar que la Constitución vietnamita no garantiza derechos inalienables como el derecho constitucional de Occidente. Las Cortes vietnamitas no pueden (por ahora) reconocer la existencia de un derecho sacando inferencias generales de la Constitución, o de los Principios Generales del Código Civil. Estos derechos son, más o menos, meras manifestaciones de la voluntad política del Estado de introducir reformas económicas"19.

5.1. Derechos Constitucionales de la persona

- Todos los ciudadanos son iguales ante la ley. (art. 52)

- El ciudadano tiene derecho a participar en la administración del Estado. (art. 53)

19 Idem, p.64 
- Todo ciudadano, independientemente de su nacionalidad, sexo, antecedentes sociales, creencia religiosa, nivel cultural, ocupación o lugar de residencia tendrá derecho al voto al cumplir los 18 años y podrá ser elegido al cumplir los 21. (art. 54)

- Derecho y obligación de trabajar. (art. 55)

- Derecho de empresa según marca la ley. (art. 57)

- Derecho a la propiedad privada de sus ingresos legales, sus ahorros, casa, bienes muebles, medios de producción, capitales y otras posesiones en la empresa u otras organizaciones económicas; en cuanto a la tierra, está regulada por los arts. 17 y 18 de esta Constitución. (art. 58)

- Derecho y obligación a recibir instrucción y formación. La Educación Primaria es obligatoria y gratuita. (art. 59)

- Derecho a realizar investigación técnica y científica, a hacer inventos y descubrimientos... El Estado protege los derechos de autor y patentes industriales. (art. 60)

- Derecho a la protección de la salud por el Estado. (art. 61)

- Derecho a construir su propia casa según los dictados de la legislación urbanística. Los derechos del arrendador y el arrendatario están protegidos por ley. (art. 62)

- Hombres y mujeres tienen los mismos derechos en las áreas política, económica, cultural, social y familiar. Está absolutamente prohibido todo acto de discriminación contra la mujer y contra su dignidad. Hombres y mujeres recibirán la misma retribución por el mismo trabajo. (art. 63)

- La familia es la célula de la sociedad. El Estado protege el matrimonio y la familia. (art. 64)

- Derecho a la libertad de residencia y movimiento dentro del país y en el extranjero. (art. 68)

- Derecho a la libertad de opinión y de expresión, libertad de prensa, derecho a ser informado, derecho de reunión, derecho a formar organizaciones y a manifestarse, según lo prescrito por la ley. (art. 69)

- El ciudadano disfrutará dela inviolabilidad de la persona y la protección de la ley en cuanto a su vida, salud, honor y dignidad. Está absolutamen- 
te prohibida toda clase de acoso, coerción, tortura, o violación de su honor y dignidad contra el ciudadano. (art. 71)

- Nadie será considerado culpable hasta que no se haya dictado sentencia por un Tribunal. (art. 72)

- El ciudadano tiene derecho a la inviolabilidad de su domicilio. Se garantiza el secreto de su correspondencia, conversaciones telefónicas y telegramas. (art. 73)

\subsection{Cultura, educación, ciencia y tecnología}

La Constitución tiene un capítulo aparte (Capt. 3ํ) sobre cultura, educación y tecnolo gía, fuertemente impregnado de valores nacionales, propios de un país joven que recientemente ha alcanzado la independencia, fundado en valores socialistas, y con un férreo control sobre cualquier "desviación ideológica", lo que puede plantear serias dificultades a la libertad de pensamiento, opinión y expresión.

"El Estado se compromete a crear condiciones favorables para promover el desarrollo integral de la persona y a ayudar en la formación de familias que sean cultas y felices, marcadas por el patriotismo, el amor al socialismo, un genuino espíritu internacionalista y de amistad y colaboración con todas las naciones del mundo" (art. 31).

“El Estado y la sociedad buscan el proteger y desarrollar la cultura vietnamita, que será nacional, moderna y humanista: heredará y promoverá los valores y culturas de las distintas nacionalidades de Vietnam, y el pensamiento, la moral y el estilo de Ho Chi Minh, la quintaesencia de la cultura humana... El Estado asume la administración general de todas las actividades culturales". El Estado protegerá y promoverá la diversidad cultural y artística (art. 32), pero "el Estado prohibirá estrictamente, también, en el campo de la cultura e información, cualquier actividad que pueda ser en detrimento del interés nacional, y destructiva de la personalidad, la moral y el estilo de vida de Vietnam". (art. 33). "La propagación de pensamiento y cultura retrógrada y depravada debe ser eliminada" (art. 30).

En esta misma línea de control ideológico, aunque se reconoce que "la educación y la formación son objetivos prioritarios" (art. 35), y que "el Estado promoverá distintos tipos de instituciones educativas: estatales, del pueblo y otras" (art. 36), se insiste en que "el Estado se hace responsable de la gestión general del sistema educativo con respecto a los objetivos, contenidos, planes de estudio, niveles exigidos a los profesores, regulación de exámenes y el sistema de certificados y diplomas. (art. 36)

Este mismo capítulo de la Constitución reconoce que "la ciencia y la tecnología juegan un papel clave en el desarrollo socioeconómico del país" 
(arts. 37-38) y que el Estado apoyará de distintas formas toda clase de investigaciones tecnológicas, especialmente en el área de salud, y dentro de este campo, en el cuidado de madres y niños (art. 39). Finalmente, "el Estado y la sociedad desarrollarán un sistema de cultura física y deportes que sea nacional, científico y popular, reservándose el Estado la gestíón general del desarrollo de esta cultura física y de los deportes" (art. 41)

\subsection{El problema de la libertad religiosa}

Para entender este problema en el contexto real del Vietnam actual, hay que verlo, no con los ojos de un Euro pa cristiana, sino en la realidad de un país que después de siglos de sometimiento a poderes extranjeros finalmente gana la independencia, consigue la unidad de todo el territorio nacional y acepta la vía socialista para el desarrollo so cioeconómico del país, y, por otra parte, ve a las religiones presentes en Vietnam como organizaciones que con frecuencia, en el pasado, apoyaron a las potencias coloniales, lucharon con el gobierno títere de Saigón contra las fuerzas del norte del país lideradas por Ho Chi Mihn o, simplemente, se opusieron a un sistema socialista que, según ellos, tenía que ser necesariamente ateo. Así pues, es natural que el go bierno haya querido siempre tener cierto control sobre todos estos grupos religiosos, para asegurarse de que todos ellos contribuirían, cosa que no hicieron en el pasado, al fortalecimiento del ideal de un Vietnam independiente, unido y socialista. En Vietnam hoy hay unos 16 millones de creyentes distribuidos en seis religiones legalizadas: budismo, cristianismo, caoismo, budistas Hoa Hao, y musulmanes. Algunas cifras nos darán idea de la importancia relativa de cada una de estas religiones.

BUDISM O. Entre las seis religiones presentes hoy en Vietnam, el Budismo Mahayana (del Gran Vehículo) procedente de China es el que aparece en primer lugar, integrando divinidades locales y animistas, así como ritos taoístas, y más tarde elementos del Budismo Zen. En nuestros días, después de enfrentarse con el Presidente católico Ngo Dinh Diem, y luego con el gobierno comunista, finalmente en 1980 se crea la Iglesia Budista Vietnamita (IBV) que adopta el pincipio rector de "budismo-nación-socialismo" y es aceptada plenamente por el gobierno actual del país.

CATOLICISMO. El catolicismo entró en Vietnam de la mano de los franciscanos que pronto fueron sustituidos por los jesuitas Ilegados de Macao. No es hasta 1933 que el Vaticano nombra el primer obispo Vietnamita, Pham Bá 


\section{CUADRO 2}

Estadísticas religiosas de Vietnam

\begin{tabular}{|c|c|c|c|}
\hline & Fieles & Lugares de culto & Clérigos \\
\hline Budistas & 7.620 .803 & 14.017 & 27.884 \\
\hline Católicos & 6.028 .480 & 5.456 & $\begin{array}{l}\text { Obispos ............ } 33 \\
\text { Sacerdotes ... } 2.200 \\
\text { Frailes .......... 1.514 } \\
\text { Religiosas .. } 10.647 \\
\text { Seminaristas ... } 548\end{array}$ \\
\hline Protestantes & 412.344 & 499 & $\begin{array}{l}\text { Pastores .......... } 161 \\
\text { Misioneros ...... } 450\end{array}$ \\
\hline Caodistas & 1.147 .527 & 1.037 & Líderes ........... 5.608 \\
\hline Hoa Hao & 1.306969 & 196 & - \\
\hline Musulmanes & 93.000 & 89 & Líderes ............. 734 \\
\hline
\end{tabular}

Fuente: Comité du Gouvernementm chargé des religions, 1997.

Tòng. Durante la guerra del Vietnam (1954-75) la fuerte campaña anticomunista de la jerarquía católica hizo que el Vicario Apostólico, primero fuera expulsado de Hanoi, y cuando el país se reunificó, también de Saigón. En los últimos años ha habido momentos de tensión entre el gobierno y la Iglesia Católica, como con ocasión de la canonización de 117 mártires vietnamitas que el gobierno consideraba que habían sido condenados, no por odio a la religión sino, simplemente, por traidores a la patria. El nombramiento a una sede episcopal de una determinada persona no aceptable por el gobierno, la formación del "Movimiento de Solidaridad de los Católicos por la Defensa Nacional" queel Vaticano consideraba como un movimiento poco menos que cismático, o la negativa del Vaticano a reconocer al primer gobierno de Ho Chi Minh "por considerarlo comunista y ateo", han creado, con frecuencia, innecesarias tensiones entre la Iglesia y el gobierno. Últimamente, sin embargo, una vez la Iglesia asumió el lema: "vivir el Evangelio en el seno de la nación por el bien de los compatriotas", se ha llegado a un "modus vivendi" que ha permitido mejorar mucho estas relaciones, como lo muestran las palabras del Presidente del Presidium del Frente Vietnamita de la Madre Patria

\section{ESTUDIOS}


(partido comunista) pronunciadas en la apertura de la VIII Conferenica Episcopal en septiembre de 2001 en el que hizo un caluroso elogio a la contribución del clero y los fieles en el proceso de renovación (Doi Moi). "Estos éxitos - dijo- se deben en parte, a la devoción de los Obispos y sacerdotes católicos que han animado a sus fieles a esforzarse a trabajar por la felicidad del país y vivir en línea con las enseñanzas de Dios"20.

PROTESTANTISMO. El protestantismo se introdujo en Vietnam a finales del siglo XIX y siempre ha aparecido bajo la sombra de actividades, reales o imaginarias, políticas. Cuando la partición del país y la declaración por Ho Chi Minn de la República de Vietnam la mayoría de protestantes, pastores y seglares, huyeron del comunismo y emigraron al sur donde recibieron el apoyo de las fuerzas norteamericanas de ocupación, lo que desprestigió a estos grupos religiosos. Pero, sin duda, lo que más empaña la imagen de los protestantes en Vietnam a los ojos del gobierno, son sus actividades entre los grupos étnicos minoritarios, algunos de los cuales han pretendido en el pasado independizarse de Vietnam y crear su propio Estado.

CAODAISMO. En los años 20, Ngô Mihn Chiêu, un pequeño funcionario de la administración de Conchinchina proclamó haber tenido contacto directo con el supremo espíritu Ilamado Cao Dài, que le había pedido fundar una nueva religión que integrase prácticas de espiritismo y telepatía junto con ideas principalmente del Budismo, el Confucionismo y el Taoísmo, Ilamándose así mismo la Gran Religión. Esta nueva religión fue desde el principio una importante fuerza política, llegando a formar su propio ejército que los franceses utilizaron para luchar contra las fuerzas independentistas de Ho Chi Mihn. Hoy, sin embargo, zanjadas las diferenicas entre sus distintos grupos, es una de las seis religiones legales del país con más de un millón de seguidores.

HÒA HÁO. Esta secta toma su nombre del pueblo donde apareció en 1939. Sus creencias son una mezcla de principios budistas, las tres verdades (Buda, Dharma y Sangha) y el culto de los antepasados. Desde el principio este grupo apareció más como un movimiento político que un grupo religioso, llegando en 1945 a fundar el Partido Socialdemócrata. Primero los japoneses y más tarde los gobiernos anticomunistas de Saigón y las fuerzas norteamericanas utilizaron a los seguidores de este grupo religioso para sus

20 "Vietnam's News. The National English Language Daily", Sábado, 22 de septiembre de 2001, pp. 1 y 3.

RFS 
fines políticos, ayudándoles a reunir un ejército de más de 20.000 hombres y unos grupos de seguridad de más de 30.000. Hoy el gobierno vietnamita reconoce como legales las actividades meramente religiosas de esta secta.

MAHOMETANOS. Hoy en día el Islam es el grupo religioso más pequeño del país, de hecho sólo se encuentra entre los miembros del pueblo Cham, sucesores de los habitantes del antiguo Reino Champa (192-1470) originario de Indonesia. El Islam practicado por este grupo está muy influenciado por los usos y costumbres locales y otras religiones tradicionales como el brahmanismo y sus creencias islámicas son muy particulares.

\subsection{Marco jurídico de la libertad religiosa hoy en Vietnam}

Antes de analizar el cuerpo jurídico que regula la libertad religiosa en Vietnam conviene recordar que ningún gobierno vietnamita, ni el del norte antes de la unificación, ni el provisional del sur, ni el unificado después de 1975 se ha declarado jamás ateo. El mismo Ho Chi Mihn en varias ocasiones mencionó la necesidad de proteger a las distintas religiones ${ }^{21}$ e insistió en la necesidad de la colaboración entre creyentes y no creyentes: "Yo pido al gobierno -escribió- que declare la libertad de creencia y la solidaridad entre creyentes y no creyentes"22.

Los instrumentos jurídicos que regulan hoy la libertad religiosa en Vietnam son: la Constitución de 1992, la Directiva del Comité Central del Partido Comunista de Vietnam del 2 de julio de 1998 (37-CT/TW) y el Decreto № 26/ 1999/ND-CP que viene a sustituir un Decreto anterior de 1991 (69/HDBT). Todos estos documentos jurídicos son, en palabras del mismo gobierno, "el primer paso en el proceso de elaboración, modificación y perfeccionamiento de una futura legislación vietnamita sobre la libertad religiosa"23 .

La Constitucion de 1992 proclama explícitamente la libertad religiosa: “EI ciudadano disfrutará de libertad de creencias y de religión; puede seguir los dictados de una religión o no seguir ninguno. Todas las religiones son iguales ante la ley. Los lugares de culto de todas las religiones y creencias están

\footnotetext{
21 "El Partido comunista lejos de perseguir a las religiones debe protegerlas" citado en El Pueblo de 27 enero 1995.

22 Ho Chi Minh (1998). Tomo IV pp. 8-9.

23 Idem, p. 119.
} 
protegidos por ley. Nadie puede violar la libertad de creencia y religión; nadie puede usar mal sus creencias o religión para violar la ley y las políticas del Estado" (art. 70). La diferencia entre "creencias" y "religión", se refiere a la libertad de conciencia y pensamiernto, la primera, y a las actividades y organizaciones religiosas, el segundo.

La Directiva del Partido Comunista del 2 de julio de 1998 empieza reconociendo que "Vietnam cuenta con numerosas religiones y decenas de millones de creyentes. Las religiones y creencias son las necesidades espirituales de una parte de la población"24, y recomienda al gobierno la elaboración de normas claras y concretas sobre las actividades de las ordenes religiosas, la creación de fondos, sus actividades financieras, culturales, sociales y artísticas así como sus relaciones exteriores; la utilización de tierras, edificios, formación del clero, publicaciones, etc. Y respondiendo a esta directriz emanada del Partido se publica el Decreto 26/1999/ND-CP del 19 de abril sobre las actividades religiosas.

El Decreto empieza declarando los principios generales de libertad de creencias y religión, la igualdad absoluta entre creyentes y no creyentes pero, así como se perseguirá toda violación de la libertad de creencias y religión, así también, dice el Decreto, se perseguirá todo abuso de las creencias y religiones que vayan en contra del Estado socialista, impidan el cumplimiento de los deberes de ciudadano, pongan en peligro la unidad de la patria y o las sanas costumbres de la nación ${ }^{25}$. Los creyentes tienen el derecho de "practicar el culto y las oraciones en su domicilio o en los lugares de culto, participar en los ritos religiosos y estudiar la religión" (art. 7) y el mismo Decreto prevé en el art. 8 que se podrán celebrar actividades religiosas fuera de los lugares de culto previa autorización de las autoridades competentes. Las organizaciones religiosas tienen el derecho a recoger fondos por medio de colectas, donaciones de individuos u organizaciones y otros ingresos legales (art. 8/4). Los Congresos y conferencias a nivel local o provincial deben ser autorizados por la autoridad (art. 10). Dado que toda la tierra es propiedad del Estado, el lugar de culto, la iglesia es de la comunidad religiosa, pero la tierra sobre la que se ha construido sigue siendo del Estado, que la cede por tiempo ind eterminado exempta de impuestos. Las reparacio-

\footnotetext{
24 Directive du Parti Communiste du Viet.Nam, 37-CT/TW du 2 juillet 1998 sur les travaux concernant les religions dans la nouvelle conjuncture. Parf.1

25 Decret 26/1999/ND/CP du 19 avril 1999 sur les activités religieuses, arts. 1 a 5.
}

\section{RFS}


nes, restauraciones o reconstrucciones de lugares de culto deben hacerse previa notificación o autorización de las autoridades (art. 12). Existe un control estatal sobre la distribución producción, comercialización o importación de materiales religiosos (art. 14) y sobre toda clase de publicaciones, aunque la iglesia católica cuenta hoy con dos semanarios: "El Católico Vietnamita" y "Catolicismo y Nación".

Quizás el tema más controvertido de este Decreto es el referente a la libertad del clero y las órdenes religiosas: la apertura de seminarios debe ser autorizada por el Primer Ministro, y su organización y actividades han de ser acordes con la reglamentación del Comité gubernamental para la religiones y el Ministerio de Educación (art. 18); las órdenes religiosas deben tener la autorización del gobierno para realizar sus actividades y el ingreso de nuevos candidatos a estas órdenes debe ser según las reglamentaciones estatales, (art. 19) es decir, deben ser autorizados por el Estado, lo mismo que la ordenación al sacerdocio una vez se han ter minado los estudios. Es cierto, sin embargo, como dice una publicación oficial del Estado que "el Comité Gubernamental para las religiones está estudiando actualmente el reajustar las formalidades y procedimientos para hacer menos inconveniente a los aspirantes a la vida religiosa. Pero mientras tanto, la autorización sigue siendo indispensable"26. El nombramiento de altos dignatarios religiosos (cardenales, obispos, bonzos, etc) debe ser aprobado por el Primer Ministro (art. 20) quien puede también presentar candidatos; las órdenes religiosas, por último, que tienen contacto con el extranjero, reciben instrucciones del extranjero o reciben miembros del extranjero deben siempre hacerlo bajo el control estatal (arts. 22 a 26).

\section{Conclusión}

Para terminar esta rápida visión del actual Vietnam, cremos que no podemos hacer nada mejor que transcribir literalmente la Conclusión de la historia quasi-oficial de Vietnam, del profesor Nguyên Khac Vien, pues este autor plantea exactamente las mismas preguntas que nosotros nos hacemos después de recorrer la difícil pero heroica evolución de aquel país.

“Debido a que el Partido Comunista ha jugado el papel dirigente en el combate por la independencia nacional, y debido a su dinamismo propio, el marxismo ha sido indiscutiblemente el catalizador más potente de la vida política y cultural desde los

\footnotetext{
26 Nguyên Mihn Quang (2001), p. 114.
} 
años 30. ¿En qué medida seguirá siéndolo, en el caso de asumir la dirección ideológica y cultural de toda la nación, de manera exclusiva? Esta pregunta está directamente ligada a otra: ¿cuáles serán las estructuras socio-políticas compatibles con la instauración de una economía de mercado? Hemos ya visto cómo la dirección actual del Partido ha rechazado toda idea de pluralismo ideológico y político. Quedan, pues, algunas preguntas en el aire. Incluso si el crecimiento económico hace acceder al país, como se espera, a un estado de prosperidad decente. ¿Cuáles serán las características propias del "socialismo vietnamita"? Actualmente el pueblo vietnamita no tiene ya que hacer frente a una agresión militar, pero sí a un peligro más insidioso: la liberalización económica y la apertura del país al capital extranjero pueden conducir al nacimiento de un "capitalismo salvaje" cuyo desarrollo podría conducir a desastres ecológicos, a la exacerbación de las desigualdades sociales, a las taras sociales de criminalidad, toxicómanos, etc. Capitalismo salvaje que moviliza a sus servicios fracciones importantes del aparato del Estado, transformándolos en una verdadera mafia, enemiga de todas formas de democracia, justicia social y protección ecológica. ¿Podrá el pueblo vietnamita impedir el nacimiento de este capitalismo salvaje, por lo menos mitigar sus estragos? El combate es duro y ciertamente de largo aliento. ¿Se exponen a llevar a enfrentamientos armados? Se trata de cuestiones que no concierne más que a los vietnamitas contestar"27.

\section{Bibliografía}

CIEM (Central Institute for Economic Development)2001-Vietnam'sEconomy in 2000. Hanoi. Statistical Publishing House.

DÂng Dúc Dam (1997), Vietnam's Macro-Economy and Types of enterprises. The current Position and Future Prospects. Hanoi. Thê Giöi Publishers.

Dietrich, Karoline and Hainz, Michael S.J . (2002), “La Libertá Religiosa in Viet Nam" en Studi e Ricerche. As. 03, pp. 229-238.

Ho CHI Minh (1998), Ho Chi Minh. Oeuvres Complètes. Hanoi. Ed. Politiques Nationales.

Kug Iñigo, Casquet Mạ Eugenia y Sjöö, Lena (1994), Vietnam. Barcelona. Ed. Laertes.

- Labour Code of the Socialista Republic of Vietnam. 1994. Hanoi. Thê Giöi Publishers.

Lanoix, Rosa (2001), "Vietnam. El difícil camino hacia la libertad" en Misioneros, $\mathrm{n}$ 일. Enero.

May Ly Quang (2001), Vietnam 2000-2001. Hanoi. Editorial Thê Giöi.

27 Nguyên Khac Vien (1997), p. 522. 
May Ly Quang (2002), Vietnam 2001-2002. Hanoi. Thê Giöi Publishers.

Nguyen Khac Vien (1997), Vietnam. Una larga Historia. Hanoi. Editorial ThêGiöi.

NGUYÊn MINH Quang (2001), Religions au Viêt Nam. Entretiens. Questions et Réponses. Hanoi. Editions Thê Giöi.

Pham Duy NghîA (2002), Vietnamese Business Law in Transition. Hanoi. Thê Giöi Publishers.

Pham Van Dinh, Takeshi Murata \& Pham Van Hung (2001), Key Issues in the Process of Rural Economy Development in Vietnam. In J Fac. Agr. Kyushu Univ., 45 (2) 643-650.

Socialista Republic of Vietnam (1993), The Constitution of 1992. Hanoi. Thê Giöi Publishers.

VARIous (1999), "Agricultural Co-operatives and Policy Issues in Japan and Vietnam". Proceedings of the $2^{\text {nd }}$ J oint Workshop at the Faculty of Economics and Rural Development. Hanoi Agricultural University. August 11 to 13.

VARIous (2001), Vietnam Economic Times. Brain Power. Getting ahead with the knowledge economy. Issue 84. February.

Varios, Viêt Nam News. The National English Language Daily. Varios números de 2001 y 2002.

VARIos (2001). "Vietnam. El negocio de la modernización". Expansión. Suplemento especial sobre Exportación. Miércoles 31 enero. 